\title{
Socioeconomic and geographical influences on primary dental care preferences in a population of young children
}

\author{
M. Tickle, ${ }^{1}$ G. Moulding, ${ }^{2}$ K. Milsom, ${ }^{3}$ and A. Blinkhorn, ${ }^{4}$
}

\begin{abstract}
Objective To compare the socioeconomic profiles of children registered in the GDS, with those using the CDS services and unregistered children. Secondly to examine the effects of socioeconomic status on travelling to access primary dental care, and finally to map out the location of unregistered children in relation to primary dental care services.
\end{abstract}

Setting The study was carried out in 1998 in Ellesmere Port in the North West of England.

Subjects and materials The study population was all children younger than 6 years who used primary dental care services in, or were residents of, Ellesmere Port. The study population was categorised into those registered with a GDS dentist, those using CDS services and those unregistered by matching GDS and CDS data to the HA population register. Socioeconomic status was measured using the Super Profiles geodemographic classification. The relationship between service preferences and travelling to access primary dental care with socioeconomic status were compared using cross-tabulations and chi square tests.

Results There was a significant socioeconomic trend evident in the use of dental services. Two thirds of those using CDS services came from the most deprived area types. Of those who were unregistered half lived in the most deprived area types compared with one third of those registered with the GDS. Those who travelled into Ellesmere Port to access primary dental care were significantly more likely to live in an affluent area. Unregistered patients were homogeneously spread across the town.

Conclusions The ability to match GDS and CDS data to the HA population register is essential to understand how dental services are used by the local population. Children from deprived areas are more likely to use the CDS and a service local to their homes, therefore primary dental care services for deprived communities have to be provided locally.

\footnotetext{
$1^{*}$ Acting Consultant in Dental Public Health, Manchester Health Authority; ${ }^{2}$ General Dental Practitioner, Ellesmere Port PDS Consortium; ${ }^{3}$ Consultant in Dental Public Health, Chester and Halton Community Trust; ${ }^{4}$ Professor of Oral Health, Turner School of Dentistry, University of Manchester

${ }^{*}$ Correspondence to: $M$. Tickle, Manchester Health Authority, Gateway House, Piccadilly South, Manchester M60 7LP

email:Martin.Tickle@mchester-ha.nwest.nhs.uk

REFEREED PAPER

Received 24.08.99; accepted 17.01.00

(C) British Dental Journal 2000; 188: 559-562
}

The health improvement programmes (HImPs) of many health 1 authorities now have an oral health component, thereby offering primary dental care practitioners a chance to play a part in improving oral health of the child population. The majority of UK children receive primary dental care through their relationship with a general dental service (GDS) dentist and the NHS considers registration to be so important that it is now one of the high level indicators used to judge the performance of health authorities. ${ }^{1}$ Registration is also encouraged by additional payments to general dental practitioners (GDPs) practising in disadvantaged areas to register children less than 5 years of age. ${ }^{2}$

Provision of primary dental care to children is not confined to the GDS. Although the community dental service (CDS) now provides more specialised services, ${ }^{3}$ most services still have a primary dental care role for children. For example, Waplington et al. found that around $9 \%$ of children aged 8 years used the CDS for their primary dental care, ${ }^{4}$ and this level of clinical intervention will have an influence on population dental care. Therefore any study examining access to dental services must be able to identify children using CDS services so that the proportion of unregistered children is not overestimated.

The use of dental services by young children is strongly related to socioeconomic status. ${ }^{5}$ Children from more affluent backgrounds tend to access primary dental care more frequently. If health authorities and practitioners are to promote dental attendance it is important to examine the service preferences of children from different social strata and also to identify where children live in relation to established dental services, whether GDS or CDS. A major barrier to understanding dental attendance has been the inability to identify those who use the GDS and the CDS, but more importantly those who use neither. Tickle et al. have shown that it is possible to match dental data sets to the health authority (HA) population register with a degree of success. ${ }^{6}$ This provides the opportunity to examine the socioeconomic profile of children using the primary dental care services in a specific locality and to compare them with those children not using primary dental care services. It also enables the location of unregistered children to be identified. Armed with this information, initiatives to promote attendance can be targeted more effectively.

The aim of this study was to examine the use of primary dental care by children under 6 years in a specific locality. The objectives were firstly to compare the socioeconomic profiles of children registered in the GDS, those using the CDS services and unregistered children. Secondly to examine the effects of socioeconomic status on travelling to access primary dental care in this age group, and 
finally to map out the unregistered children in relation to existing primary dental care services.

\section{Method}

The study took place in the town of Ellesmere Port, South Cheshire in 1998. All 21 GDPs in the six general dental practices have come together as a consortium to provide primary dental care to residents of the town under a first-wave personal dental services (PDS) pilot. The data collected relates to the situation prior to the pilot going live, when all of the GDPs were working in the GDS. PDS pilots test new ways of commissioning primary dental care services according to local needs. The Ellesmere Port pilot aims to provide a service for all of the residents in the town and so the identification of the GDS, CDS and unregistered populations was important. All of the GDPs gave permission for files of their patients to be supplied by the DPB to the health authority. The CDS provides primary dental care in two clinics in Ellesmere Port, and supplied information on all patients who were in treatment or awaiting recall. Therefore the data provided by the CDS was broadly analogous to GDS registration data. Both the GDS and CDS data sets were read into Microsoft Access, cleaned and aggregated to make a single data file.

The process used to match the GDS/CDS data file to the HA population register has been described in detail elsewhere. ${ }^{6}$ The matching process enabled those residents who were unregistered or not accessing their care in the CDS to be identified, and these subjects were added to the dental data file. This study was confined to young children; therefore all subjects less than 6 years of age were separated out. By referring to the postcodes in the data set each subject's enumeration district code (EDs are the smallest areas of the census geography with a population of about 400 ), the grid reference of their postcode and the relevant 'Super Profiles' geodemographic classification codes ${ }^{7}$ were added. The Super Profiles classification categorises EDs according to their socioeconomic and demographic characteristics using census variables.

Table 1 Results of the matching process for children under 6 years: dental records with HA population register

\begin{tabular}{lrrrr}
\hline & $\begin{array}{c}\text { Matched } \\
\mathrm{n}(\%)\end{array}$ & $\begin{array}{c}\text { Unmatched } \\
\mathrm{n}(\%)\end{array}$ & $\begin{array}{r}\text { Total } \\
\mathrm{n}(\%)\end{array}$ \\
\hline GDS & $2,039(90.7)$ & $208(9.3)$ & 2,247 & $(90.7)$ \\
CDS & $219(94.6)$ & $12(5.4)$ & 231 & $(9.3)$ \\
Total & $2,258(91.2)$ & $220(8.8)$ & $2,478(100.00)$ \\
\hline
\end{tabular}

A series of analyses were undertaken to compare the characteristics of users of the CDS, the GDS and unregistered children. The target market level of the Super Profiles geodemographic classification was used to divide the population into socioeconomic quintiles as described by Tickle et al. ${ }^{8}$ The socioeconomic status of children in contact with the two primary dental care services and those who were unregistered were compared using cross-tabulation and chi-squared tests for trends. In like manner the socioeconomic status of children travelling from outside Ellesmere Port to access GDS services in the town was compared with those living in Ellesmere Port and accessing services locally. Finally the location of the postcodes of unregistered patients were mapped as points in relation to the location of existing services, using the map info geographical information system (GIS).

\section{Results}

The results of the matching exercise between the dental data sets and the HA population register are shown in Table 1. Some 208 (9.3\%) GDS records failed to match with the records in the HA register. In the CDS a smaller proportion (5.4\%) failed to match. Closer scrutiny of the 220 unmatched records revealed that 107 of these records $(48.6 \%)$ could be categorised by either partial postcodes or addresses as living outside Ellesmere Port. Of the remaining records $48(21.8 \%)$ had partial postcodes which suggested they were Ellesmere Port residents. The remaining 65 records $(29.5 \%$ and $2.6 \%$ of all records) had empty postcode and address fields and therefore no clue as to whether or not they were Ellesmere Port residents. In all 2,900 Ellesmere Port residents aged under 6 years and present on the HA register were not present in the dental data sets, and therefore classified as unregistered. This gave a final study population of 5,378. After the matching process $96.7 \%(N=2,173)$ of GDS patients and $97.4 \%(N=225)$ of CDS patients could be georeferenced, that is an ED code or grid reference could be assigned to the subject's postcode. All 2,900 residents added from the HA population register could be georeferenced.

There were no significant differences at the $P<0.05$ level by gender between children registered with the GDS (males 52.1\%: females $47.9 \%$ ), CDS patients (males $55.4 \%$ : females $44.6 \%$ ) or unregistered children (males $51.0 \%$ : females $49.0 \%$ ). A significant $(P<0.0001)$ linear trend was found in the numbers accessing primary dental care by birth cohort. Less than $5 \%$ of children under the age of 1 year had accessed care, compared with $67 \%$ of those aged 5 years.

Table 2 Ellesmere Port children aged 0-5 years in contact primary dental care (CDS and GDS) or unregistered: by socioeconomic status

\begin{tabular}{|c|c|c|c|c|c|c|c|}
\hline \multicolumn{6}{|c|}{ Target market quintiles $N(\%)$} & \multirow[t]{2}{*}{ Total $N(\%)$} & \multirow[t]{2}{*}{$P$} \\
\hline & $\begin{array}{c}1 \\
\text { affluent }\end{array}$ & 2 & 3 & 4 & $\begin{array}{c}5 \\
\text { deprived }\end{array}$ & & \\
\hline GDS & $\begin{array}{c}301 \\
(13.85)\end{array}$ & $\begin{array}{c}834 \\
(38.38)\end{array}$ & $\begin{array}{c}120 \\
(5.52)\end{array}$ & $\begin{array}{c}184 \\
(8.47)\end{array}$ & $\begin{array}{c}734 \\
(33.78)\end{array}$ & $\begin{array}{c}2,173 \\
(41.02)\end{array}$ & $<0.0001$ \\
\hline Unregistered & $\begin{array}{c}264 \\
(9.10)\end{array}$ & $\begin{array}{c}794 \\
(27.38)\end{array}$ & $\begin{array}{c}125 \\
(4.31)\end{array}$ & $\begin{array}{c}269 \\
(9.28)\end{array}$ & $\begin{array}{c}1,448 \\
(49.93)\end{array}$ & $\begin{array}{c}2,900 \\
(54.74)\end{array}$ & \\
\hline CDS & $\begin{array}{c}11 \\
(4.89)\end{array}$ & $\begin{array}{c}42 \\
(18.67)\end{array}$ & $\begin{array}{c}9 \\
(4.00)\end{array}$ & $\begin{array}{c}13 \\
(5.78)\end{array}$ & $\begin{array}{c}150 \\
(66.67)\end{array}$ & $\begin{array}{c}225 \\
(4.24)\end{array}$ & $<0.0001$ \\
\hline Total & $\begin{array}{c}576 \\
(11.06)\end{array}$ & $\begin{array}{c}1,670 \\
(31.52)\end{array}$ & $\begin{array}{c}254 \\
(4.79)\end{array}$ & $\begin{array}{c}466 \\
(8.80)\end{array}$ & $\begin{array}{c}2,332 \\
(44.02)\end{array}$ & 5,298 & \\
\hline
\end{tabular}

Unregistered $/ G D S=\chi^{2}$ for trend 148.03, $\mathrm{df}=1, P<0.0001$

Unregistered $/ C D S=\chi^{2}$ for trend $20.08, \mathrm{df}=1, P<0.0001$ 
Table 3 Children aged 0-5 years registered with an Ellesmere Port GDS dentist: those living inside and outside Ellesmere Port by socioeconomic status

\begin{tabular}{|c|c|c|c|c|c|c|}
\hline & \multicolumn{5}{|c|}{ Target market quintiles $N(\%)$} & \multirow[t]{2}{*}{ Total N $(\%)$} \\
\hline & $\begin{array}{c}1 \\
\text { affluent }\end{array}$ & 2 & 3 & 4 & $\begin{array}{c}5 \\
\text { deprived }\end{array}$ & \\
\hline $\begin{array}{l}\text { Registered with a } \\
\text { GDP and live in } \\
\text { Ellesmere Port }\end{array}$ & $\begin{array}{c}181 \\
(9.79)\end{array}$ & $\begin{array}{c}715 \\
(38.67)\end{array}$ & $\begin{array}{c}80 \\
(4.33)\end{array}$ & $\begin{array}{c}160 \\
(8.65)\end{array}$ & $\begin{array}{c}713 \\
(38.56)\end{array}$ & $\begin{array}{c}1849 \\
(85.09)\end{array}$ \\
\hline $\begin{array}{l}\text { Registered with a } \\
\text { GDP and live } \\
\text { outside Ellesmere } \\
\text { Port }\end{array}$ & $\begin{array}{c}120 \\
(37.04)\end{array}$ & $\begin{array}{c}119 \\
(36.73)\end{array}$ & $\begin{array}{c}40 \\
(12.35)\end{array}$ & $\begin{array}{c}24 \\
(7.41)\end{array}$ & $\begin{array}{c}21 \\
(6.48)\end{array}$ & $\begin{array}{c}324 \\
(14.91)\end{array}$ \\
\hline Total & $\begin{array}{c}301 \\
(13.85)\end{array}$ & $\begin{array}{c}843 \\
(38.38)\end{array}$ & $\begin{array}{c}120 \\
(5.52)\end{array}$ & $\begin{array}{c}184 \\
(8.47)\end{array}$ & $\begin{array}{c}734 \\
(33.78)\end{array}$ & 2173 \\
\hline
\end{tabular}

$\chi^{2}$ for trend $162.21, \mathrm{df}=1, P<0.0001$

Table 2 compares those registered with a GDS dentist, those unregistered, and those accessing their care in the CDS, according to socioeconomic status. Significant differences were found between CDS patients and unregistered residents $(P<0.0001)$, and between registered patients and unregistered residents $(P<0.0001)$. One third of GDS patients lived in EDs in the most deprived quintile compared with one half of unregistered residents, but two thirds of CDS patients were resident in areas found in the most deprived quintile.

Table 3 summarises the relationship between socioeconomic status and travelling to access GDS services. Out of the 2,478 children registered with a GDP, 2,173 $(96.7 \%)$ could be allocated a Super Profiles target market code. Of this total 1,849 (85.1\%) were resident in the 115 EDs making up the town of Ellesmere Port. Chil- dren travelling into Ellesmere Port to access primary dental care were significantly more likely $(P<0.0001)$ to live in more affluent areas than those accessing their care locally. Only $5.6 \%(N=13)$ of CDS patients were resident outside Ellesmere Port compared with $14.6 \%$ of GDS patients.

Figure 1 presents a dot density map that shows the location of unregistered children in Ellesmere Port in relation to the siting of primary dental care services. The children were geographically evenly distributed across the town; no clustering was apparent.

\section{Discussion}

This study gives a sense of the proportions of children accessing care in the two primary dental care services compared with the unregistered population in a specific locality. The GDS provided the major-
Fig 1 Dot density map showing the position of unregistered patients in relation to the location of primary dental care sites in Ellesmere Port

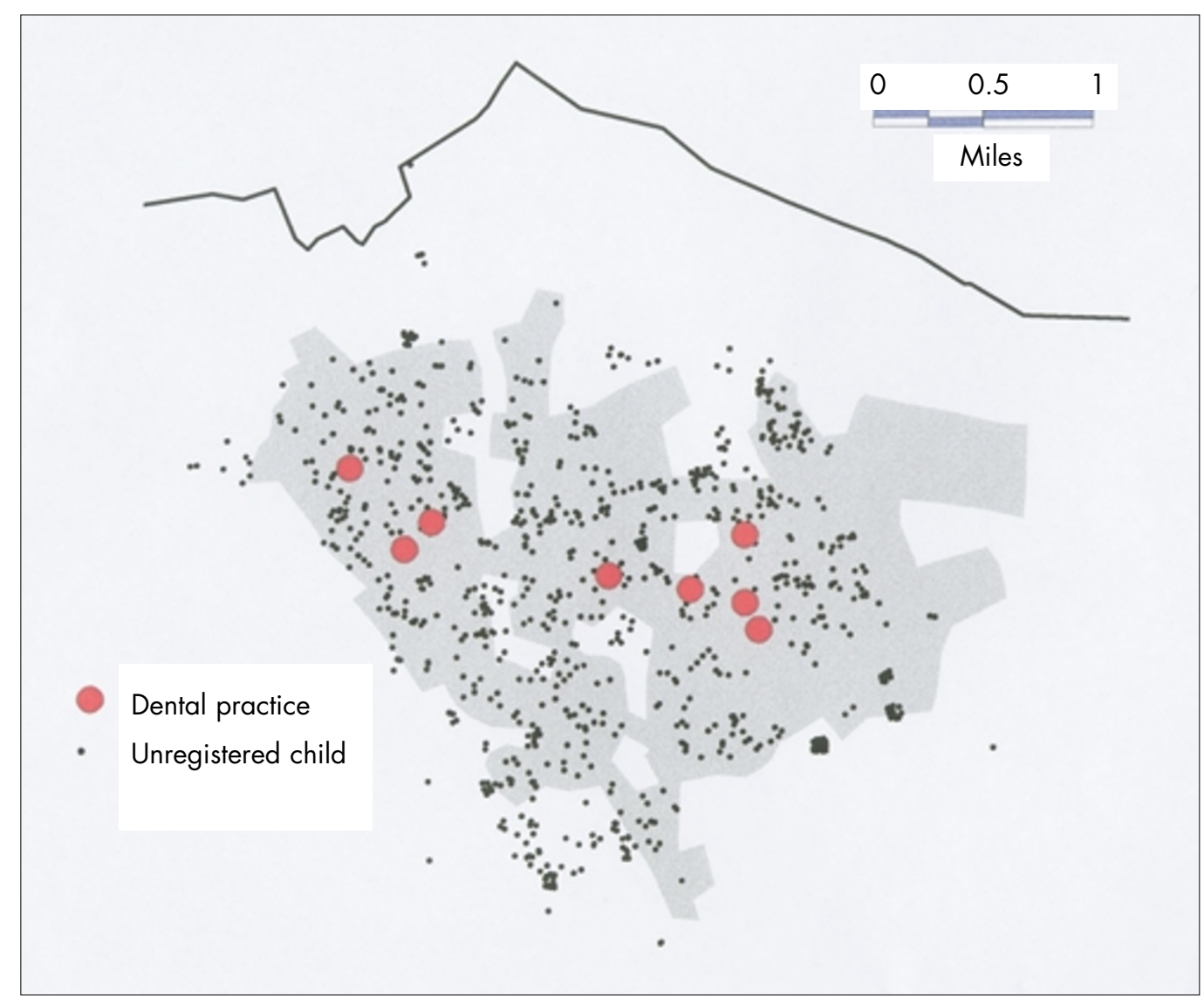


ity of care for young children under NHS terms and conditions. Discussions with the GDPs revealed that virtually no children received independently funded primary dental care.

The CDS service in Ellesmere Port operates, and is monitored according to a service specification agreed with the Health Authority. This specification follows the national policy for CDS services, ${ }^{3}$ which is to provide primary dental care for those who are unsuited for, or unable to access care in the GDS. Interestingly the number of CDS patients under 6 years as a proportion of all patients $(N=231,9.3 \%)$, was much higher than that in the GDS $(N=2247,5.7 \%)$. The greater numbers of young children in the CDS is probably a reflection of the traditional role of the CDS as a treatment service for children. However this may also be a result of demand for CDS services from poorer families, as there was a highly significant difference according to socioeconomic status between the children using the CDS service and those who were unregistered or registered with GDS services. Indeed, a socioeconomic status trend was evident across the three categories. Children who used the CDS service were more likely to come from the most deprived areas. Unregistered children were more likely to live in less deprived EDs than those using the CDS, whereas children using the GDS were more likely to live in more affluent areas than unregistered children.

These findings agree with other studies, ${ }^{4,9}$ that children from disadvantaged families are more likely to use the CDS than to register with the GDS. However this study has shown that those using the CDS service were more likely to have a disadvantaged background than unregistered patients. The location of the CDS clinics would seem to have had little effect on this pattern, as a dot density map showed no evidence of geographical clustering of CDS patients. The pattern could be caused by contractual reasons, for example a school screening policy. In Ellesmere Port there is no referral to the CDS from screening and the Health Authority service specification dictates that all children, other than a very few with special needs, are referred to the GDS. The role of the CDS should be complementary to the GDS. ${ }^{3}$ Therefore in different parts of the country the patient-base of the CDS should vary according to the local stresses on the GDS, and therefore these findings are not necessarily generalisable to other areas. For example, if an area has a major GDS access problem, the CDS would have a greater 'safetynet' role and would be expected see more adult patients. However, in Ellesmere Port there is no GDS access problem, and it would seem that children from a deprived background preferentially use the CDS. This may be because of parental preferences. Dental attendance of young children is closely associated with mother's attendance, ${ }^{10}$ more affluent families tend to use the GDS and this could account for the differences found in the socioeconomic status profiles of the GDS registered and unregistered children. Adults from deprived backgrounds are less likely to be regular dental attenders and one of the main reasons for this is anxiety associated with dental treatment. ${ }^{11}$ It could be that parents of deprived children may feel that they will be less likely to be pressured into attending themselves, if they take their children to the CDS rather than the GDS. This is one hypothesis to account for the significant differences found. The reasons why deprived families have this strong reliance on the CDS should be investigated. It could be that the CDS are providing a valuable service for the poorest in society. However, the consequences of this reliance will have to be examined in terms of the way the CDS is perceived by the population. It may be that the CDS is seen as primary dental care service for the poor and those with a disability. If this is the case, attendance at the CDS could lead to stigmatisation of disadvantaged children making them less likely to attend a GDS dentist as they grow up.
Children who travelled into Ellesmere Port to access care were more likely to come from a more affluent background than those children who accessed their care locally. This was also reflected by the fact that only 13 (5.6\%) of the more deprived CDS-patient base travelled into Ellesmere Port for care. This is probably related to car ownership, which is a strong proxy for income. ${ }^{12}$ This finding has important implications when deciding where to locate new services to reduce inequalities in access to primary dental care. Services must be sited locally if children from deprived backgrounds are to attend on a regular basis.

The unregistered population made up the majority (53.9\%) of the study population and this is the population to which programmes to promote primary dental care attendance have to be targeted. The dot density map (Fig. 1) which pinpoints the geographical location of the unregistered children showed that they were homogeneously spread across the town. Therefore for this community, although there were inequalities evident in service use, a geographically targeted approach to promote service use would be inappropriate. Attempts to increase registration will have to be through a whole community approach.

\section{Conclusion}

The ability to match GDS and CDS data to the HA population register, used in tandem with geodemographic classifications and GIS can enable public health and primary care dentists to start to understand how services are used by the local population and therefore aid targeting and planning decisions. Children from deprived areas are more likely to use the CDS and a service local to their homes, therefore primary dental care services for deprived communities have to be provided locally. The reasons and consequences for the reliance of disadvantaged families on the CDS should be examined, similarly the reasons for preferentially attending the GDS should be analysed, in order to determine how best the two services can work together to promote the dental attendance of unregistered children.

1 Department of Health. The new NHS Modern and Dependable: A national framework for assessing performance consultation document. EL (98) 4, 1998. London: HMSO.

2 Department of Health. General Dental Services HSC 1998/042, 1998B London: HMSO

3 Department of Health. Primary care dental services HSG(97)4, 1997 London: HMSO.

4 Waplington J A, White D A, Clarke J R. A comparison of the social backgrounds and dental health of patients attending the Community Dental Service, the General Dental Service and non registered patients. Community Dent Health 1998; 15: 150-154.

5 Silver D H. A comparison of 3-year-old's caries experience in 1973, 1981, and 1989 in a Hertfordshire town, related to family behaviour and social class. Br Dent J 1992; 172: 191-197.

6 Tickle M, Hayhurst G, Moulding G, Jenner A M, Blinkhorn A S. Matching Dental Practice Board data to the Health Authority Population Register Community Dent Health 1999 (in press).

7 Batey P W J, Brown P J B. From human ecology to customer targeting: the evolution of geodemographics. In: P Longley, G Clarke (eds) GIS for Business and Service Planning. London: Longman,1995.

8 Tickle M, Williams M J, Jenner A M, Blinkhorn A S. The effects of dental attendance and socioeconomic status on dental caries experience and treatment patterns in 5-year-old children. Br Dent J 1999; 186: 135-137.

9 Prendergast M J, Beal J F, Williams S A. The relationship between deprivation, ethnicity and dental health in 5-year-old children in Leeds, UK. Community Dent Health 1997; 14: 18-21.

10 O'Brian M. Children's Dental Health in the United Kingdom 1993. London: HMSO, 1994.

11 Todd J E, Lader D. Adult Dental Health 1988 United Kingdom. London: HMSO, 1991.

12 Jones S. Identifying deprived areas using indices from the 1991 census and information about the recipients of community charge and council tax benefit. J Epidemiol Community Health 1995; 49(Suppl2): S65-S71. 